\title{
Modern Contraceptive Utilization and Its Associated Factors among Indigenous and Nonindigenous Married Women of Reproductive Age Group in Jigiiga Town, Eastern Ethiopia, 2018
}

\author{
Hagos Degefa Hidru $\mathbb{D}^{1},{ }^{1}$ Tariku Dingeta, ${ }^{2}$ Bezatu Menigiste ${ }^{\circ},{ }^{3}$ Berhe Etsay, ${ }^{1}$ \\ Haftay Gebremedhin $\mathbb{D}^{1},{ }^{1}$ Meresa Berwo $\mathbb{D}^{3},{ }^{3}$ and Guesh Gebreayezgi Asefa $\mathbb{D}^{4}$ \\ ${ }^{1}$ Department of Public Health, College of Medicine and Health Sciences, Adigrat University, Adigrat, Ethiopia \\ ${ }^{2}$ School of Public Health, College of Medicine and Health Sciences, Haramaya University, Haramaya, Ethiopia \\ ${ }^{3}$ Department of Midwifery, College of Medicine and Health Sciences, Adigrat University, Adigrat, Ethiopia \\ ${ }^{4}$ School of Public Health, Department of Epidemiology and Biostatistics, Aksum University, Aksum, Ethiopia \\ Correspondence should be addressed to Hagos Degefa Hidru; hagosdeg@gmail.com
}

Received 23 November 2019; Revised 28 April 2020; Accepted 11 May 2020; Published 27 May 2020

Academic Editor: Maria Barbolina

Copyright (c) 2020 Hagos Degefa Hidru et al. This is an open access article distributed under the Creative Commons Attribution License, which permits unrestricted use, distribution, and reproduction in any medium, provided the original work is properly cited.

\begin{abstract}
Background. The use of birth control and its promotion has potential benefits of reducing poverty, maternal, and child mortality. However, there is limited evidence regarding modern contraceptive utilization among indigenous and nonindigenous married women of the reproductive age group in Ethiopia. Therefore, this study aimed to assess the magnitude of modern contraceptive utilization and its associated factors among indigenous and nonindigenous married women in Eastern Ethiopia. Methodology. A community based comparative cross-sectional study design was conducted among married women of the reproductive age group from February 01 to March 01/2018 in Jigjiga town, Eastern Ethiopia. A total of 1004 married women were selected using a simple random sampling method. The collected data were entered into EpiData software version 3.1 and exported to SPSS version 22.0 for analysis. Bivariable and multivariable logistic regression analyses were used to identify the associated factors. Statistical significance was declared using 95\% confidence interval and $p$ value of less than 0.05 . Result. A total of 987 study participants were included in the study with a response rate of $98.3 \%$. The overall prevalence of modern contraceptive utilization among married reproductive age group women was found to be $19.9 \%$ (95\% CI (17.4\%-22.3\%) with $26.5 \%$ and $11.4 \%$ for nonindigenous and indigenous women, respectively. Primary level of education (AOR 0.84; $95 \%$ CI (0.15-0.85) $p$ 0.0001) and Somali in ethnicity (AOR 0.75; 95\% CI (0.15-0.94) p 0.03) were associated factors among indigenous group, while age group 30-34 years (AOR 1.56; 95\% CI (1.31-9.52) p 0.02) and being a housewife in occupation (AOR 0.49; 95\% CI (0.42-0.96) p 0.04) were the associated factors among the nonindigenous group. Conclusion. Overall utilization of modern contraceptives was approximately one-fifth, with markedly lower use among indigenous participants. One-third of nonindigenous and less than one-seventh of indigenous were utilizing modern contraceptive methods. There is a need to further explore and understand the factors across indigenous and nonindigenous women for the use of modern contraceptives; hence, a longitudinal study is desirable.
\end{abstract}

\section{Introduction}

Family planning refers to intention planning of when to have children through the use of birth control measures. It means the use of contraceptives or other steps that allows individuals and couples to anticipate and have their desired number of children as well as to achieve healthy spacing and timing of their birth. Family planning has the potential benefits of reducing poverty, maternal, and child mortality that is occupying a critical role in the health and development of a population [1-3]. 
Globally, many obstacles remain to ensuring that women of reproductive age realize their right to modern contraception and reproductive health $[4,5]$. Despite their desire to avoid or delay pregnancy, according to UNFPA 2010, around 215 million women in developing countries rely on traditional methods only, which have a high failure rate, or did not use any contraceptive methods at all. Given this unaddressed need for modern contraception, over 300,000 women die as a result of maternal or pregnancy-related complications each year $[6,7]$.

Globally, contraceptives help to prevent an estimated 2.7 million infant deaths and the loss of 60 million of healthy life in a year. At least 22,500 women died from unsafe abortion complications, 74 million unplanned pregnancies occur every year in the developing world $[8,9]$. Avoiding different factors associated with the use of contraceptive methods could avert globally 54 million unintended pregnancies (80 per 1,000 women in Africa), 79,000 maternal deaths and one million infant deaths each year [10]. Though contraceptive utilization has a comprehensive benefit for women, it was one of underutilized public intervention in the least developed countries particularly low in Africa (33\%), in Central and Southeast Asia with only 47\%, whereas in Ethiopia, according to EDHS 2016 report, only 35\% are using a modern contraceptive method $[11,12]$.

Also besides, the region has very low modern contraceptive coverage; according to EDHS 2016 report, it accounts for around $1.5 \%$ coverage as compared to other regions $56 \%$ in Addis Ababa, $47 \%$ in the Amhara region $[6,13]$. However, it is of great interest to fill evidence-based the gap of why poor modern contraceptive utilization practices myriad obstacles as a result of factors such as lack of information, inability to take family decisions on their own, religions, desire number of family size, distance from health facilities, fear of side effects, and long waiting hour at the same time inadequate knowledge among indigenous and nonindigenous married women's of reproductive age group was assessed. Therefore, this study aimed to assess the magnitude of modern contraceptive utilization and its associated factor among indigenous and nonindigenous married women of reproductive age group.

\section{Materials and Methods}

2.1. Study Design and Period. A community based comparative cross-sectional study design was conducted among indigenous and nonindigenous married women of the reproductive age group in Jigjiga town, Eastern Ethiopia, from February 01 to March 01/2018.

2.2. Sample Size Determination and Sampling Technique. The sample size was determined using a single population proportion formula by considering a confidence level of $95 \%=$ 1.96, the margin of error $=0.04$, and $p=0.50$ for both groups, because there are no studies done before on the region like this comparative among indigenous and nonindigenous groups. The calculated sample size was 280 for nonindigenous and 357 for indigenous, respectively, by using their target population 1037 (nonindigenous) and 5097 (indigenous) and by considering the $5 \%$ nonresponse rate and a design effect of 1.5 , the final sample size was 1004 (441 nonindigenous and 563 indigenous). The multistage cluster sampling technique was used to reach a household level. A total of 1004 study participants were proportionally allocated based on the households from each sub kebeles, and then, a simple random sampling technique was used to identify study participants (Figure 1).

2.3. Data Collection Method. The data was collected through face-to-face interviewer-administered questionnaire. After extensive revision of the English questionnaire, the final English version was translated into local language by language expertise. The principal investigator trained the data collectors and supervisor for five consecutive days on instruction for the method; how to take informed written consent, how to approach participants, ethical procedure, and general information on modern contraceptive and the objective of the study. Eight university student fluent local language speakers (Somali and Amharic) and one supervisor were recruited.

2.4. Data Quality Control. The questionnaire was pretested on $5 \%$ of the study population in the nonselected kebeles to ensure clarity, wordings, logical sequence, and skip patterns of the questions. Appropriate modifications were made after discussing with the supervisor and data collectors before starting the actual data collection process. Every day the filled questionnaire was checked before a respondent goes from the setting by data collectors and supervisor.

2.5. Data Processing and Analysis. The completed data was entered using Epi-Data statistical software version 3.1 and then exported to SPSS version 22 for final analysis. Frequencies and percentages were used to present categorical data. The household wealth index was also constructed by using Principal Component Analysis (PCA). Odds ratios (ORs), 95\% confidence intervals (CIs), and $p$ value were calculated using a logistic regression model to determine association levels of predictors to the outcome variables. All variables with $p$ value $\leq 0.15$ were taken into the multivariable model to control for all possible confounders, and the variables were selected by all methods. A multivariable logistic regression analysis was used to estimate the adjusted OR of predictors to modern contraceptive utilization by controlling confounding factors. A variable having $p<0.05$ was considered a statistically significant variable in all models. Before the inclusion of predictors to the final logistic regression models, the multicollinearity was checked using $\mathrm{VIF}<10$, tolerance tests $>0.1$, and standard error. The goodness of fit of the final logistic model was tested using Hosmer and Lemeshow test at a value of $>0.05$.

2.6. Operational Definitions. Nonindigenous women: married women of reproductive age group (15-49 years) who were not born in the region but currently native and living in the region for more than six months [14].

Indigenous women: married women of reproductive age group (15-49 years) were native, i.e., women who were born and living in the region irrespective of their ethnicity [14]. 


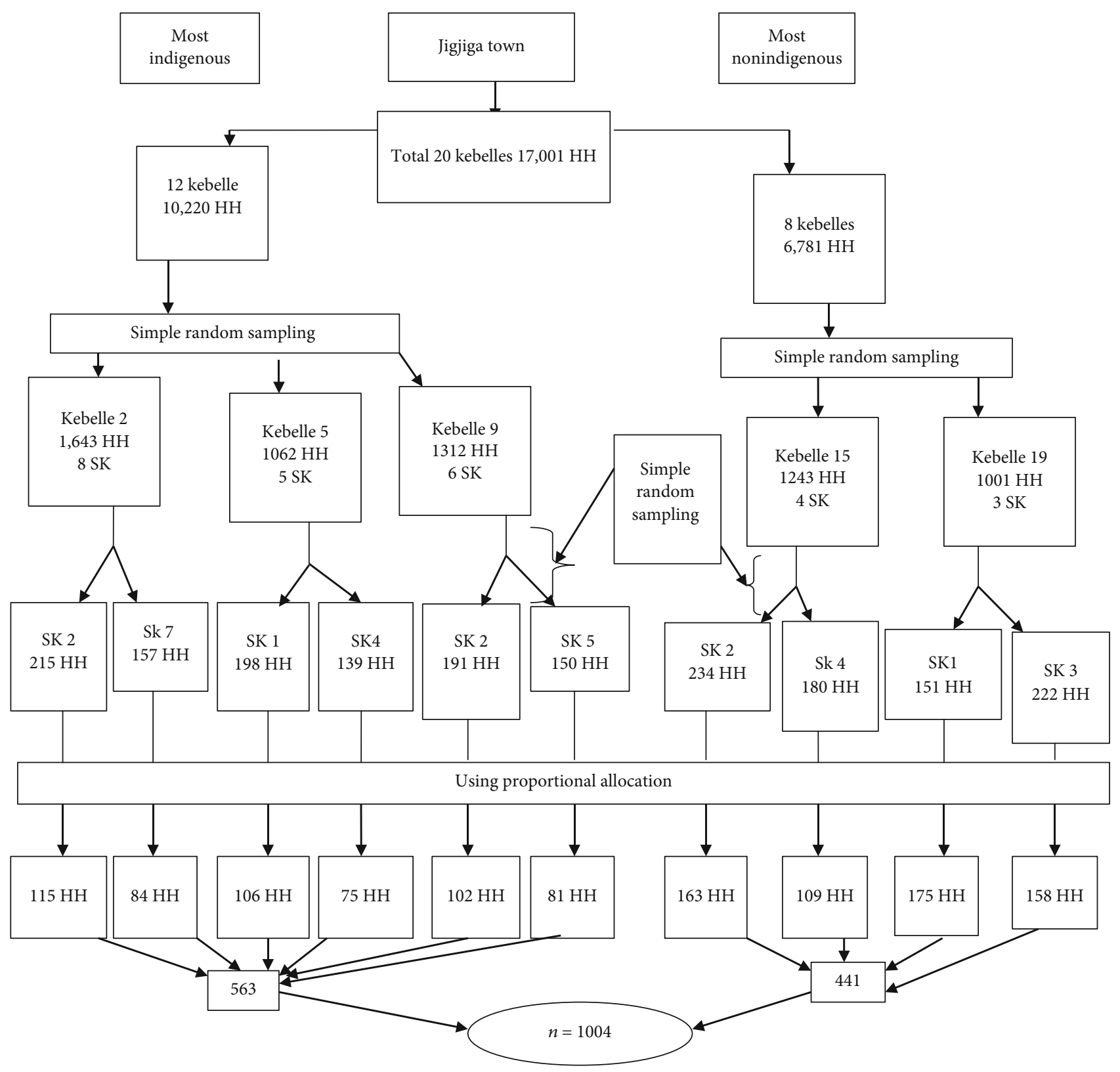

SK -sub kebele

HH -House hold

$n$ - total sample size

FIGURE 1: Schematic presentation of the sampling procedure of indigenous and nonindigenous married reproductive age group women in Jigjiga Town, Eastern Ethiopia, February1-March 1/2018.

Utilization: use of any modern contraceptive method to space child and to protect unwanted pregnancy during the age of $15-49$ years [15].

Modern contraceptive: refers to methods of child spacing or birth control other than natural methods like pill, Norplant, injectable, and IUCD [14].

Good knowledge: those women who scored points above or equal to the mean of the knowledge related questions on modern contraceptive utilization; those women who had scored points below the mean value were considered as poor knowledge.

\section{Result}

3.1. Socio-Demographic Characteristics of Study Participant. A total of 987 study participants were included in the study with a response rate of $98.3 \%$. The mean age of nonindigenous and indigenous women was $(29.6+8.3)$ and $(28.8+7.5)$ years, respectively. More than one-fourth of the respondents $160(28.8 \%)$ were in the age group of 20-34, and more than one-fifth of the respondents $106(24.5 \%)$ were 25-29 age group for indigenous and nonindigenous, respectively. Considering the religion, $509(91.7 \%)$ of the 
TABLE 1: Socio-demographic characteristics of married reproductive age group women of indigenous and nonindigenous groups in Jigjiga Town, Eastern Ethiopia, February1-March1/2018.

\begin{tabular}{|c|c|c|c|c|c|}
\hline \multirow{2}{*}{ Variables } & & \multicolumn{2}{|c|}{ Indigenous $(N=555)$} & \multicolumn{2}{|c|}{ Nonindigenous $(N=432)$} \\
\hline & & Frequency & Percent & Frequency & Percent \\
\hline \multirow{3}{*}{ Education } & No formal education & 190 & 34.2 & 160 & 37 \\
\hline & Primary level & 100 & 18 & 72 & 16.6 \\
\hline & Secondary and above & 265 & 47.8 & 200 & 46.4 \\
\hline \multirow{6}{*}{ Occupation } & Government employee & 83 & 15.0 & 60 & 13.9 \\
\hline & Private employee & 68 & 12.3 & 56 & 13.0 \\
\hline & Merchant & 143 & 25.8 & 122 & 28.2 \\
\hline & Unemployed & 65 & 11.7 & 47 & 10.9 \\
\hline & Housewife & 144 & 25.9 & 105 & 24.3 \\
\hline & Student & 52 & 9.4 & 42 & 9.7 \\
\hline \multirow{6}{*}{ Ethnicity } & Somali & 452 & 81.4 & 28 & 6.5 \\
\hline & Amhara & 71 & 12.8 & 191 & 44 \\
\hline & Oromo & 21 & 3.8 & 44 & 10.2 \\
\hline & Tigray & 6 & 1.1 & 80 & 18.5 \\
\hline & Gurage & 5 & 0.9 & 65 & 15 \\
\hline & & Wolayta & & 24 & 5.8 \\
\hline \multirow{3}{*}{ Religion } & Muslim & 509 & 91.7 & 200 & 46.3 \\
\hline & Orthodox & 40 & 7.2 & 188 & 43.5 \\
\hline & Protestant & 6 & 1.1 & 44 & 10.2 \\
\hline \multirow{7}{*}{ Age group } & $15-19$ & 20 & 3.6 & 3 & 0.7 \\
\hline & $20-24$ & 131 & 23.6 & 95 & 22.5 \\
\hline & $25-29$ & 127 & 22.9 & 79 & 18.7 \\
\hline & $30-34$ & 83 & 15 & 69 & 16.3 \\
\hline & $35-39$ & 130 & 23.4 & 105 & 24.8 \\
\hline & $40-44$ & 50 & 9 & 47 & 11 \\
\hline & $45-49$ & 14 & 2.5 & 25 & 6 \\
\hline
\end{tabular}

indigenous and 200 (46.3\%) of nonindigenous were Muslim followers (Table 1). Concerning their live pattern 482 (78.8\%) of indigenous and 370 (96\%) of nonindigenous respondents were currently living with their husbands. Three hundred fifty-one (63.2\%) indigenous and 357 (82.6\%) nonindigenous respondents stated that their husband had no other wife. Five hundred two (90.5\%) of indigenous and $380(87.9 \%)$ nonindigenous respondents had children.

3.2. Contraceptive Knowledge. From the total, 137 (68.8\%) of indigenous and $129(68.3 \%)$ of nonindigenous respondents had good knowledge. A total of 153 (60\%) indigenous and $127(37 \%)$ nonindigenous respondents knew the injectable type of contraceptive method (Figure 2). Two hundred sixty-two (47.2\%) of indigenous and 278 (64.4\%) of nonindigenous respondents knew at least one importance of modern contraceptive. More than two-thirds of the indigenous and nonindigenous groups had known the importance of contraceptive as pregnancy prevention. A total of 303 (54.6\%) and $303(70.1 \%)$ indigenous and nonindigenous respondents, respectively, had heard about modern contraceptive, and more than half of these respondents, 177

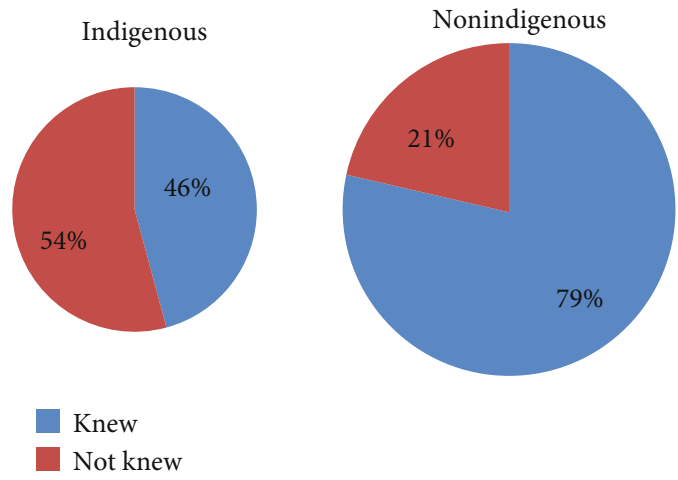

FIgURE 2: Frequency of indigenous and nonindigenous married reproductive age group women knowing any type of modern contraceptive in Jigjiga Town, Eastern Ethiopia, February1-March $1 / 2018$.

(58\%) of indigenous and 170 (56\%) of nonindigenous groups, were heard from the health professional.

3.3. Factors Related to Utilization of Modern Contraceptive Method. A total of 98 (17.7\%) indigenous and 230 (53.2\%) 


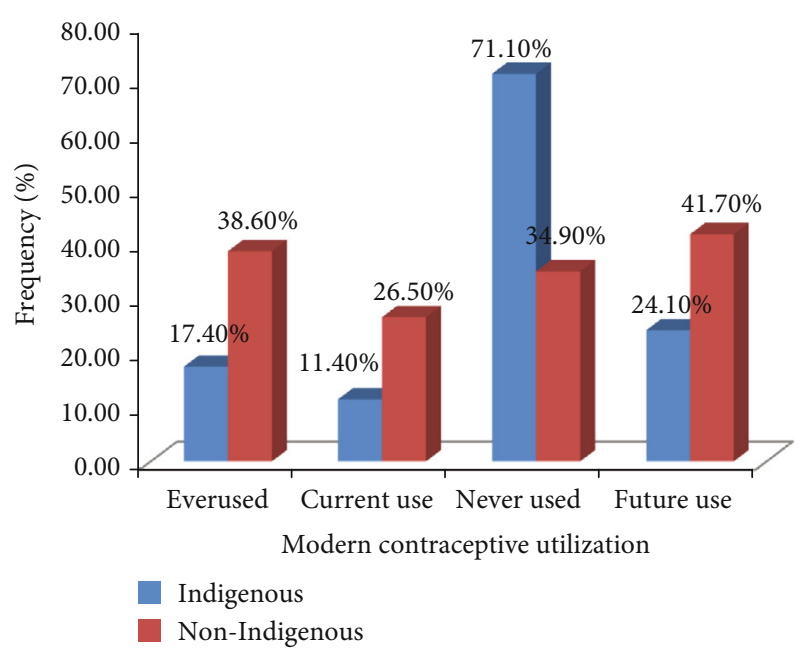

FIGURE 3: Frequency of indigenous and nonindigenous married reproductive age group women on utilization modern contraceptive in Jigjiga Town, Eastern Ethiopia, February1-March $1 / 2018$

nonindigenous respondents had discussed modern contraceptive utilization with their husbands. Those experiencing waiting hour to get reproductive health service, 105 (52\%) of indigenous and 323 (94\%) of nonindigenous respondents were feeling short waiting hour, respectively.

Regarding the utilization of modern contraceptives only, $97(17.40 \%)$ of indigenous and $167(38.60 \%)$ of nonindigenous women have ever used any type of modern contraceptive. Of these reported users, $81(83.5 \%)$ indigenous and $127(76 \%)$ nonindigenous respondents have used the injectable method of contraceptive with more than half of indigenous 77 (55.8\%) and nonindigenous 116 (55.5\%) women receiving this method from nearby health posts. Sixty-three (11.4\%) of indigenous and $114(26.50 \%)$ of nonindigenous were current modern contraceptive users. From the current user, 45 (71.4\%) and 71 (62.3\%) of indigenous and nonindigenous received their contraceptives from local health posts (Figure 3).

\subsection{Factors Significantly Associated with Modern} Contraceptive Utilization. Nonindigenous women with the age group of $20-24$ years [(AOR $=2.32,95 \%$ CI: $(1.65$, $8.94)$ ] and $30-34$ years [(AOR $=1.56,95 \%$ CI: $(1.31,9.52)$ ] were 2.32 and 1.56 times more likely, respectively, to utilized modern contraceptives compared to age group 45-49 years. Those who had no formal education [(AOR $=0.74,95 \% \mathrm{CI}$ : $(0.27,0.96)]$ were $26 \%$ less likely to utilize modern contraceptive as compared to those with secondary and higher educational status. Housewives [(AOR $=0.49,95 \%$ CI: $(0.42,0.96)$ ] were $51 \%$ less likely to utilized modern contraceptive as compared to government employees. Women who had never used contraceptives because of the desire number of children [(AOR $=0.75,95 \%$ CI: $(0.52,0.94)]$ were $25 \%$ less likely to utilize modern contraceptive as compared to those who had lack of knowledge (Table 2).

Indigenous women ages $20-24$ years [ $(\mathrm{AOR}=2.87,95 \%$ CI: $(1.7,9.20)]$ were 2.87 times more likely to utilize modern contraceptives as those in the age group of $45-49$ years. Women with no formal education $[(\mathrm{AOR}=0.34,95 \% \mathrm{CI}$ : $(0.56,0.96)]$ and primary level of education $[(\mathrm{AOR}=0.84$, $95 \%$ CI: $0.84(0.15,0.85)]$ were $66 \%$ and $16 \%$ less likely to utilize modern contraceptive, respectively, as compared to secondary and above educational status. Being a housewife in occupation $[(\mathrm{AOR}=0.23,95 \% \mathrm{CI}:(0.17,0.76)]$ was $77 \%$ less likely to utilize modern contraceptive than a governmental employer. Those of Somali ethnicity [(AOR $=0.75,95 \%$ CI: $(0.15,0.94)]$ were $25 \%$ less likely to utilize modern contraceptives as compared to their Amhara counterpart. Those experiencing waiting times of less than one hour to get reproductive health services [(AOR $=2.21,95 \% \mathrm{CI}$ : $(2.51,9.53)$ ] were 2.21 times more likely utilized modern contraceptive as compared to those waiting time greater than one hour. For women who have never used because of the desired number of children $[(\mathrm{AOR}=0.65,95 \% \mathrm{CI}$ : $(0.20,0.95)]$ and for those whose religious disallows contraception $[(\mathrm{AOR}=0.52$, $95 \%$ CI: $(0.12,0.82)]$, they were $35 \%$ and $48 \%$ less likely to utilize modern contraceptive as compared to those who lacked knowledge (Table 2).

\section{Discussion}

In this study, the overall prevalence of modern contraceptive utilization among married reproductive age group of women was $19.9 \%$; $95 \%$ CI $(17.4 \%-22.5 \%)$ with $26.50 \%$; $95 \%$ CI: (20.6\%-31.8\%) for nonindigenous and $11.4 \%$; $95 \%$ CI (8.6\%-13.9\%) for indigenous participants. The difference among indigenous and nonindigenous might be due to those indigenous women who are more desired to children, because they are encouraged by their religious beliefs and lack of education, and information towards modern contraceptive as compared to the nonindigenous group. The findings of our results are lower when compared with a study done in Mexico, $58.3 \%$ of indigenous and $73.5 \%$ of nonindigenous [16]. The findings of this study were also lower than a study conducted in Tanzania (32.9\%), Holeta Town (69.1\%), and SNNPR $(53.3 \%)[13,17,18]$. This variance might relate to the differences in awareness, knowledge on importance of modern contraceptive utilization, desired number of children, a sample, and the period of the study.

The findings of the study about husband approval to utilize were similar to a study done in Bale Zone, Nigeria, Wolaita, and Nekmet women who were discussed with their husbands and approved to use modern contraceptives [3, 15, $19,20]$. Another study done in Gambela found the prevalence of $11.5 \%$ which is similar to our study findings, whereas a study done in Bangladesh among indigenous women showed $25.1 \%$ prevalence. Such difference might be attributed to differences in accessibility, service utilization, and knowledge towards modern contraceptive utilization in the current study $[14,21]$. A study done in Gambela among nonindigenous found $36.4 \%$ prevalence which might reflect the difference in access to information, religion, fear of side effects, desired number of children, and lack of awareness on the importance of modern contraceptive utilization in the current study [21]. Studies done in Nigeria and Nekemet found that women with no formal education were less likely 


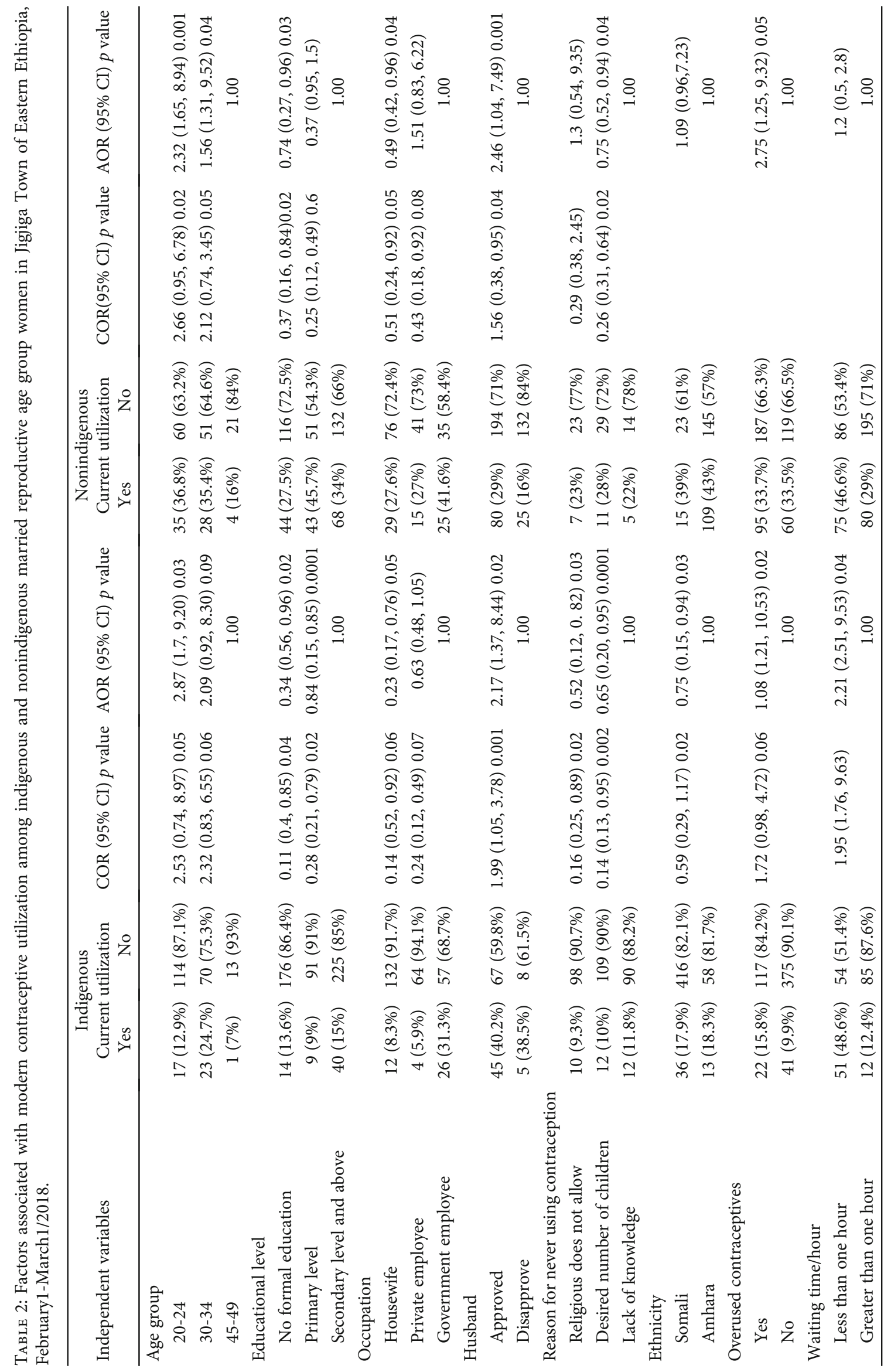




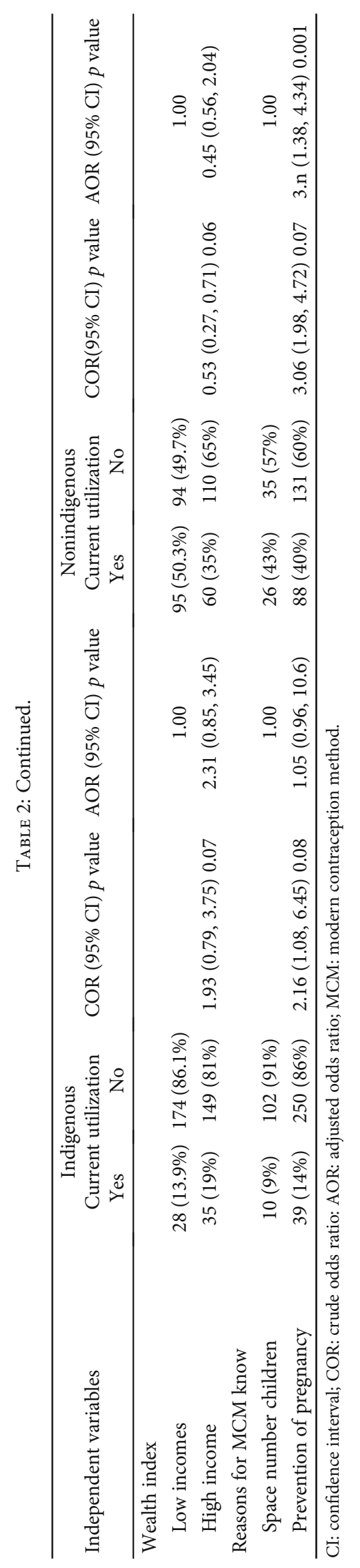


to utilize modern contraceptive which is similar to the findings of this study $[15,20]$. Other studies done in Bahirdar, Gambella, and Ghana found women 20-24 years were more likely to utilize modern contraceptives than other age groups, which again is a similar finding to the current study $[13,14,22]$.

4.1. Limitations. Since the study was cross-sectional, it might not show the temporal relation between the independent and dependent variables. The information collected was mainly through interviews, especially data collection tools for modern contraceptive utilization based on recall from the time marriage to the collection date. There may be a possibility that some of the responses might suffer from recall bias which may affect the results of the studies.

\section{Conclusion and Recommendation}

Generally, the overall utilization of modern contraceptives was approximately one-fifth, with markedly lower use among indigenous participants. One-third of nonindigenous and less than one-seventh of indigenous were utilizing modern contraceptive methods. Factors associated with utilization were belonging to the age group of 20-24 years, having no formal education, being a housewife, approved by husband, and having never used because of the desired number of children in both indigenous and nonindigenous groups. Being between 30 and 34 years was an associated factor among nonindigenous women, while the primary level of education, being Somali in ethnicity, and waiting time were the associated factors of indigenous respondents.

There is a need to further explore and understand the factors across indigenous and nonindigenous women for the use of modern contraceptives; hence, a longitudinal study is desirable. Further, it is important to share this information and evidence with decision makers and health care workers in order to address issues such as knowledge deficits on the use of modern contraceptions to inform programming and services offered.

\section{Data Availability}

The data used to support the findings of this study are available from the corresponding author upon request.

\section{Ethical Approval}

Ethical clearance was secured by Haramaya University Institutional Health Research Ethics Review Committee (IHRERC) and official permission was obtained from Jigjiga Town Health Office and Municipal. Informed written consent was also obtained from each participant after the purpose of the study and confidentiality issues were clearly explained.

\section{Conflicts of Interest}

The authors declare that they have no competing interests.

\section{Authors' Contributions}

$\mathrm{HDH}$ was the principal investigator who contributed to the conception and design of the study, collected, entered, analyzed, interpreted the data, wrote the research and manuscript, and acted as the corresponding author. TD, BM, BE, $\mathrm{HG}, \mathrm{MBM}$, and GG contributed to data analysis, interpretation, and drafted the manuscript. Provided consultancies on the reasons contributing to unfavorable management outcomes and on recommendations forwarded. All authors read and approved the final manuscript.

\section{Acknowledgments}

Our gratitude goes to the staff of the Jigjiga Town Health Office, Jigjiga Town Municipality, and Jigjiga Town health extension workers, data collectors, supervisors, study participants, and questionnaire translators into the local languages and all coauthors for contributing, helping, guiding, and commenting the manuscript. Our special gratitude also goes to Professor Pammla Petrucka from the (University of Saskatchewan Canada, College of Nursing, (through academics without borders) for helping us on language and grammar editing, and editing and reviewing of the whole manuscript.

\section{References}

[1] O. Asekun, Awareness, use and barriers to family planning services among female students at the National University of Lesotho, Roma, Lesotho, AJOL, 2010.

[2] F. A. Osore, Barriers faced by young adult females in accessing modern contraceptive methods in mukuru kwa njenga slums, nairobi citycounty, 2016.

[3] E. Asekun-Olarinmoye, W. O. Adebimpe, J. O. Bamidele, O. O. Odu, Asekun-Olarinmoye, and Ojofeitimi, "Barriers to use of modern contraceptives among women in an inner city area of Osogbo metropolis, Osun State, Nigeria," International Journal of Women's Health, vol. 2013, p. 647, 2013.

[4] M. Ndayizigiye, Assessment of Barriers of Contraceptive Use in Rural Burundi: A Mixed Methods Study. Master's thesis, Harvard Medical School, 2014.

[5] A. H. Ouma, Socio-economic and cultural barriers to utilization of contraceptives among women in ndhiwa district, homa bay county, kenya, 2010.

[6] M. Endriyas, A. Eshete, E. Mekonnen, T. Misganaw, M. Shiferaw, and S. Ayele, "Contraceptive utilization and associated factors among women of reproductive age group in Southern Nations Nationalities and Peoples' Region, Ethiopia: crosssectional survey, mixed-methods," Contraception and Reproductive Medicine, vol. 2, no. 1, 2017.

[7] J. Underwood, Trends in Contraceptive Use Worldwide, United Nations, 2016, ST/ESA/SER.A/349(Sales No. E.16.XIII.13 ISBN 978-92-1-151546-6 eISBN 978-92-1-057775-5 Copyright (C) United Nations.

[8] F. Najafi-Sharjabad, S. Z. S. Yahya, H. A. Rahman, M. H. Juni, and R. A. Manaf, "Barriers of modern contraceptive practices among Asian women: a mini literature review," Global Journal of Health Science, vol. 5, no. 5, pp. 181-192, 2013.

[9] Agency CS, Ethiopia Demographic and Health Survey 2016 Addis Ababa, Ethiopia ICF international Calverton, Maryland, USA, 2016. 
[10] M. Ubeda, "Center for Reproductive Rightsand UNFPA," 2010, http://www.reproductiverights.org.

[11] J. Yarger, M. Decker, C. Brindis, R. Cortez, and M. QuinlanDavidson, "Socioeconomic differences in adolescent sexual and reproductive health:family planning," 2015, https:// openknowledge.worldbank.org/handle/10986/22589.

[12] C. P. Petruney, Meet the Demand for Modern Contraception and Reproductive Health, 2016.

[13] P. A. Apangaet, "Factors influencing the uptake of family planning services in the Talensi District, Ghana," 2015, http://www .panafrican-med-journal.com/content/article/20/10/full/.

[14] Z. Tafese, Comparative study on utilization of modern child spacing methods and factors affecting its use among indigenous and non-indigenous women of reproductive age group in gambella town, south west of Ethiopia, South-West Ethiopia, 2003.

[15] S. S. Belda, M. T. Haile, A. T. Melku, and A. K. Tololu, "Modern contraceptive utilization and associated factors among married pastoralist women in Bale eco-region, Bale Zone, South East Ethiopia," BMC Health Services Research, vol. 17, no. 1, p. 194, 2017.

[16] J. T. Bertrand, V. M. Ward, and R. Santiso-Gálvez, Family Planning in Mexico the Achievements of 50 Years, USAID MEASURE Evaluation, 2015.

[17] S. Sita, Assessment of the magnitude and determinants of unmet need for family planning among currently married women in urban and periurban community in Hawassa, southern Ethiopia, Addis Abeba Universty, 2003.

[18] T. Girma and A. Sultan, "Prevalence and Factors Influences Utilization of Modern Contraceptive Methods among Married Women of Reproductive Age Group (15-49 Years) in Holeta Town, Oromia, Ethiopia 2016," Journal of Pregnancy and Child Health, vol. 3, no. 4, 2016.

[19] B. Megabiaw, "Awareness and utilization of modern contraceptives among street women in North-West Ethiopia," BMC Women's Health, vol. 12, no. 1, 2012http://www .biomedcentral.com/1472-6874/12/31.

[20] M. Feyisso, T. Belachew, A. Tesfay, and Y. Addisu, "Differentials of modern contraceptive methods use by food security status among married women of reproductive age in Wolaita Zone, South Ethiopia," Archives of Public Health, vol. 73, no. 1, 2015.

[21] R. Islam, Maternal Morbidity and Mortality among Indigenous People in Bangladesh: A Study of the Mru Community, Norway Spring, 2010.

[22] T. Tekelab, A. S. Melka, and D. Wirtu, "Predictors of modern contraceptive methods use among married women of reproductive age groups in Western Ethiopia: a community based cross-sectional study," BMC Women's Health, vol. 15, no. 1, 2015. 